\title{
Kinetics of Circulating Corticosterone in Infant Rats
}

\author{
LUCY L. LEEPER, ROXANN SCHROEDER, AND SUSAN J. HENNING \\ Department of Biology, University of Houston, Houston, Texas 77204
}

\begin{abstract}
Corticosterone plays an important role in the regulation of postnatal development in the rat. Basal concentrations of plasma corticosterone increase markedly during the 3rd wk of life. To date, however, the physiologic bases of this increase have remained unclear. To understand the determinants of circulating concentrations of corticosterone during this period, the plasma half-life of disappearance at steady state $\left(t_{1 / 2}\right)$, the apparent volume of distribution, and metabolic clearance rate were determined after injection of a tracer dose of ${ }^{3} \mathrm{H}$-corticosterone in rats at 12, 16, and 22 days of age. The $t_{1 / 2}$ for total plasma corticosterone decreased with increasing age. The volume of distribution decreased even more steeply and, consequently, the MCR displayed a highly significant decline between 12 and 22 days of age. As plasma concentrations of corticosteroid-binding globulin are known to increase markedly during this period, the $t_{1 / 2}$ of protein-bound corticosterone was measured and that of free corticosterone was computed. At all ages the $t_{1 / 2}$ of bound corticosterone was less than that of free corticosterone. Protein binding of the injected ${ }^{3} \mathrm{H}$-corticosterone increased significantly with development. Thus, increased binding of corticosterone is associated with decreased $t_{1 / 2}$. The increasing association of corticosterone with corticosteroid-binding globulin during this developmental period is the most likely explanation for the steep decline of volume of distribution and thus of the metabolic clearance rate for corticosterone. The latter provides, for the first time, an understanding of the basis of the developmental increase in plasma concentrations of corticosterone. (Pediatr Res 24: 595-599, 1988)
\end{abstract}

\section{Abbreviations}

$t_{1 / 2}$, half-life of disappearance

$V_{d}$, apparent volume of distribution

MCR, metabolic clearance rate

CBG, corticosteroid-binding globulin

BW, body weight

In the neonatal rat, circulating concentrations of corticosterone increase markedly between 12 and 22 days of age $(1,2)$. Previous studies using adrenal tissue in vitro have found no evidence for increased production of corticosterone with increased age (3). Although negative data cannot be viewed as proof of constant production, there are other supporting data for this concept. The circulating plasma concentration of $\mathrm{ACTH}$ remains approximately constant throughout the first $3 \mathrm{wk}$ of postnatal life, so

Received December 1, 1986; accepted July 12, 1988

Correspondence and reprint requests Dr. S. J. Henning, Department of Biology, University of Houston, Houston, TX 77204.

Supported by Grant RO1-HD-14094 from the National Institutes of Health and by a Grant-in-Aid of Research from Sigma Xi, the Scientific Research Society. that increasing levels of the trophic hormone are not responsible for the ontogenic rise $(4,5)$. In addition, the developmental pattern for cholesterol ester hydrolase, the enzyme thought to be rate limiting in substrate supply for corticosterone production, is opposite that for corticosterone (6). Thus, it has been suggested that the developmental increase in plasma corticosterone may reflect reduced removal of corticosterone from the circulation rather than increased production. There are no data in the literature for corticosterone clearance in developing rats, so the first aim of this investigation was to determine the MCR for corticosterone at 12,16 , and 22 days of age.

The $V_{d}$ is an important determinant of the rate of clearance and thus of the circulating concentration of any hormone (7). To date there are no published values for the $V_{d}$ of corticosterone in rats during the 2 nd and 3 rd postnatal wk. Because $C B G$, the high-affinity carrier of corticosterone, exhibits an ontogenic increase during this same period $(1,2,8,9), V_{d}$ would be expected to decline progressively during development. Therefore, our second aim was to measure the $\mathrm{V}_{\mathrm{d}}$ for corticosterone in rat pups at 12,16 , and 22 days of age.

Traditionally, protein-bound hormones have been thought to serve as inactive reservoirs of hormone in the circulation (10). This suggests that CBG binding should protect corticosterone from degradation. The third aim of the present investigation was to more fully assess the influence of hormone binding on the metabolism of corticosterone by determining the plasma $t_{1 / 2}$ for bound and free forms as well as for total corticosterone during development.

\section{MATERIALS AND METHODS}

Chemicals. $\left[1,2,6,7-{ }^{3} \mathrm{H}(\mathrm{N})\right]$ corticosterone $(85.8-104 \mathrm{Ci} / \mathrm{mmol})$ was obtained from New England Nuclear Corp. (Boston, MA). All other chemicals were reagent grade.

Animals. Timed-pregnant rats of the Sprague-Dawley strain (Charles River Crl:CD(SD)BR, Wilmington, MA) were received on day 15 of gestation and housed in individual opaque polystyrene cages. The animal quarters were maintained at $21 \pm 1^{\circ} \mathrm{C}$ on a 12-h light/12-h dark cycle with lights on at $0600 \mathrm{~h}$. Food (Rodent Laboratory Chow 5001, Ralston Purina Co., St. Louis, MO) and deionized water were available ad libitum. On the due date the cages were checked repeatedly for births, and the date of birth was designated as day 0 . Approximately $24 \mathrm{~h}$ postpartum, the litter size was adjusted to eight to nine pups. All pups remained with their dams until the time of the experiment. All litters were isolated in a separate room in the animal quarters from the previous evening until the morning of the experiment so as to minimize environmental stress before the experimental manipulations.

Experiment 1. Kinetic parameters were determined in rats aged 12,16, and 22 days after a single injection, under ether anesthesia, of a trace quantity of $\left[1,2,6,7{ }^{3} \mathrm{H}(\mathrm{N})\right.$ corticosterone in $0.9 \%$ saline via the femoral vein. Preliminary experiments established that sequential blood sampling was not feasible in these 
small animals. Thus, after injection with ${ }^{3} \mathrm{H}$-corticosterone $(0.2$ $\mu \mathrm{Ci} / \mathrm{g} \mathrm{BW})$, groups of pups were killed at $2,30,60,90$, and 120 min $(0900$ to $1100 \mathrm{~h})$. Trunk blood was collected in heparinized tubes on ice, and the fresh plasma was extracted with chloroform to separate corticosterone from its metabolites (11). The radioactivity remaining in the chloroform phase (total ${ }^{3} \mathrm{H}$-corticosterone) was determined as a function of time. Due to the dual constraints of single-animal time points and the dose-dependent nature of pharmacokinetic analysis, the data were grouped so that closely matched doses of radioactivity (i.e. animals with closely matched BW) were followed with time. Each grouping was termed a trial. The area under plasma concentration-versustime curves was computed using a method based on the Lagrange technique (12), and model-independent kinetic parameters of $t_{1 / 2}$, $\mathrm{V}_{\mathrm{d}}$, and MCR for corticosterone were generated. The kinetic parameters were determined for each trial, then the mean $\pm \mathrm{SE}$ for each parameter was calculated from several trials (as given in figure legend). Because $V_{d}$ and MCR are dependent on the size of the animal, these parameters were expressed on a BW basis. The elimination rate constant used to calculate MCR was determined by the 60 - through 120 -min time points.

Experiment 2. Plasma disappearance of CBG-bound and free forms of ${ }^{3} \mathrm{H}$-corticosterone during the period of steady-state elimination (30-120 min) was followed in the same rats used in experiment 1 . Fresh plasma was treated with charcoal as described by Martin et al. (13) to remove corticosterone not bound to CBG. The charcoal supernatant was extracted with chloroform to determine bound ${ }^{3} \mathrm{H}$-corticosterone. Comparison with values for total corticosterone (from experiment 1) allowed computation of the ${ }^{3} \mathrm{H}$-corticosterone that was in the free state at each time point. The logarithmic transformation of the radioactivity in both the bound and free state was plotted as a function of time. The resulting data were nearly linear and therefore straight lines of best fit for steady state were determined by the leastsquares method. $t_{1 / 2}$ for both bound and free corticosterone were determined. Total $t_{1 / 2}$ as calculated by area under the curve (experiment 1 ) was compared to total $t_{1 / 2}$ (experiment 2 ) generated by least square analysis. Paired $t$ tests showed the difference in $t_{1 / 2}$ to be nonsignificant. This indicates that, in agreement with studies in adult rats (14), the disappearance of corticosterone at steady state closely approaches first order kinetics.

Experiment 3. The percentage of circulating corticosterone which was $\mathrm{CBG}$-bound was calculated using the values for bound ${ }^{3} \mathrm{H}$-corticosterone as compared to total ${ }^{3} \mathrm{H}$-corticosterone. By analogy with the in vitro method of Martin et al. (13), these data reflect the endogenous hormone occurring in the bound state.

Statistics. Effects of age on kinetic parameters and binding profiles were assessed by the analysis of variance. The Student Neuman-Keuls test $(p=0.05)$ was used to make post hoc comparisons between groups means. Paired $t$ tests were used for a priori comparisons when appropriate.

\section{RESULTS}

Experiment 1. $t_{1 / 2}$ for total corticosterone declined through day 22 (Fig. $1 A$ ), with the period between days 16 and 22 showing the greater rate of decrease. With increasing age, $V_{d}$ declined even more steeply such that by day 22 , its value was less than $25 \%$ that of the initial value (Fig. $1 B$ ). Most importantly, MCR for corticosterone (Fig. 1C) also decreased significantly with increasing age. Analysis of variance indicated that the effect of age on $t_{1 / 2}, V_{\mathrm{d}}$, and MCR was statistically significant $(p<0.001$ in each case).

Experiment 2. The plasma clearance of total corticosterone as determined in experiment 1 was further investigated by following the individual fates of both CBG-bound and free forms of the hormone. Bound corticosterone was determined directly from plasma samples and is represented in Figure 2. Bound $t_{1 / 2}$ declined significantly with increasing age as shown by analysis of variance $(p<0.002)$. A disappearance curve for the free fraction of ${ }^{3} \mathrm{H}$ corticosterone was generated from the data for total and bound forms of the hormone. The free $t_{1 / 2}$ (Fig. 2) was found to be significantly greater than the bound $t_{1 / 2}$ at all ages $(p<0.05$ by paired $t$ tests).

Experiment 3. Circulating concentrations of CBG have previously been reported to increase during the period 16-22 days (1, $2,8,9)$. Such an increase should result in greater binding of endogenous corticosterone in the older animals. To verify that this was occurring, plasma from animals in experiment 1 was analyzed for the proportion of endogenous corticosterone that was CBG bound. Figure 3 shows that with increasing age of the animals, a significantly greater percentage of plasma corticosterone was present in the CBG-bound state $(p<0.001)$.
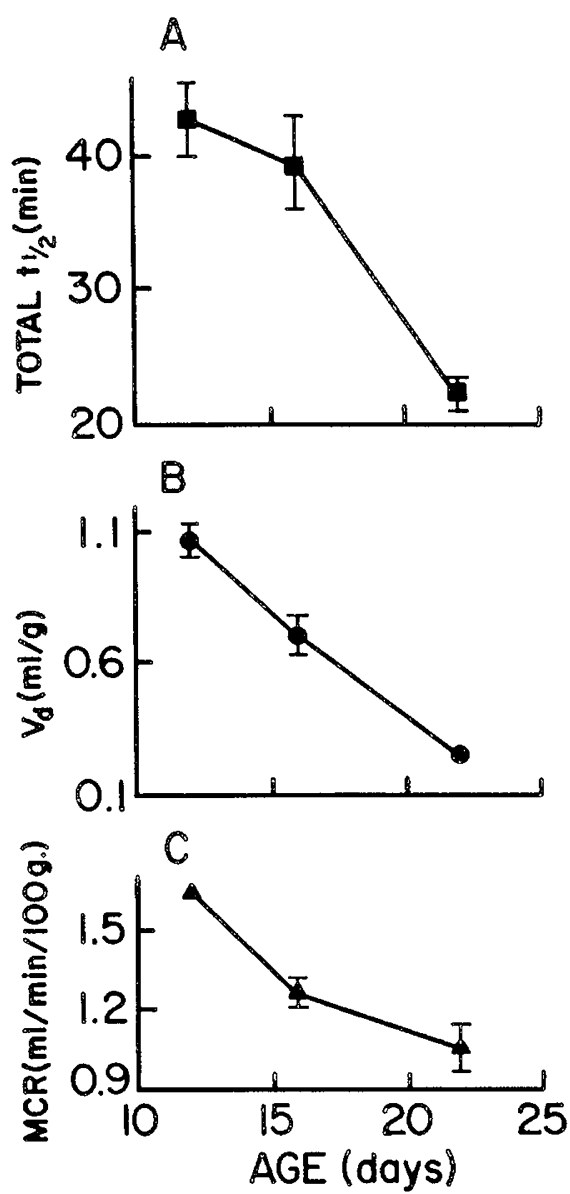

Fig. 1. Effect of age on kinetic parameters of plasma corticosterone in infant rats. $A, t_{1 / 2}$ for total corticosterone; $B, \mathrm{~V}_{\mathrm{d}}$ for total corticosterone; $C$, MCR for total corticosterone. Values are given as mean $\pm \mathrm{SE}(n=7-$ 9 trials). Absence of error bars indicates SE was smaller than symbol.

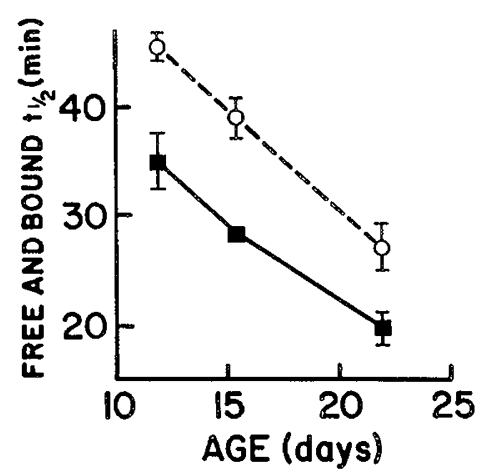

Fig. 2. Effect of age on disappearance of free and bound ${ }^{3} \mathrm{H}$-corticosterone from plasma: closed symbols show bound form and open symbols show free form. Values are given as mean $\pm \operatorname{SE}(n=7-9$ trials). Absence of error bars indicates SE was smaller than symbol. 


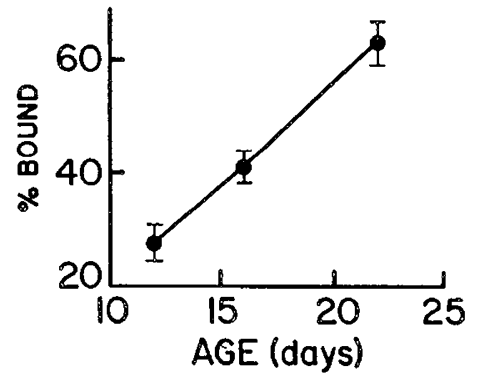

Fig. 3. Effect of age on $\mathrm{CBG}$ binding of plasma corticosterone in infant rats. The percentage of ${ }^{3} \mathrm{H}$-corticosterone in the bound state was determined at 30 min postinjection. Values are given as mean $\pm \mathrm{SE}$ ( $n$ $=7-8$ trials).

\section{DISCUSSION}

We have previously suggested that the effect of postnatal age on circulating concentrations of corticosterone in the rat may be exerted largely through changes in the clearance of the hormone (3). The data in Figure $1 C$ confirm this hypothesis. MCR decreased sharply from day 12 through day 16 and then continued its decline at a slower rate. This pattern is the mirror image of that for endogenous plasma corticosterone, which increases markedly between days 12 and 22 . Taken together with the lack of evidence for increased adrenal production of corticosterone during this age period, these MCR data make a convincing case that the developmental increase in circulating corticosterone that occurs in the rat during the 2 nd and 3 rd postnatal weeks is due entirely to declining clearance with increasing age.

It is of interest to assess the physiologic basis of this decline in clearance. As noted in "Materials and Methods," although the MCR values were obtained by a model-independent analysis of the disappearance data, these data agreed very closely with those derived from a model based on first order kinetics. In such a model, MCR is given by the equation: $\mathrm{MCR}=\ln 2 \mathrm{~V}_{\mathrm{d}} / t_{1 / 2}$. This equation is useful in identifying the factors contributing to the decline in MCR with increasing age. Inasmuch as $t_{1 / 2}$ declines with age, it cannot be the principal determinant of the developmental pattern for MCR because the declining $t_{1 / 2}$ would cause an increase in MCR. Rather, it is clear that the declining $V_{d}$ is the critical factor in that the effect of the $V_{d}$ decline outweighs that of the $t_{1 / 2}$ decline. This is not surprising because the data in Figure 1 show that for $t_{1 / 2}$, the value at 22 days is $52 \%$ of the $12-$ day value whereas for $V_{d}$, the corresponding figure is $24 \%$.

Our data showing decreasing $t_{1 / 2}$ for total corticosterone with development are in general agreement with those of Schapiro et al. (15). However, whereas Schapiro et al. (15) found widely varying values for $t_{1 / 2}$ until day 18 , we find the variation in $t_{1 / 2}$ to be modest at all ages (Fig. 1A). The scatter in their data may be related to variability in equilibration of the exogenous steroid as a result of either the route of injection (intracardiac) or the vehicle ( $10 \%$ ethanol solution). Our values for $t_{1 / 2}$ at 22 days of age are half those of Schapiro et al. (15) but compare well with those of other investigators using adult male animals and similar experimental techniques (14). Considering the sex difference in $t_{1 / 2}$ for adult animals $(14,16,17)$, male rats constitute the more valid group for comparison with sexually immature animals. At the youngest age studied (day 12), our value for $t_{1 / 2}$ is very similar to that reported for rats aged 2,6, and 7 days; moreover, Koch et al. found $\mathrm{V}_{\mathrm{d}}$, rather than $t_{1 / 2}$, to be the primary effector for decreasing MCR during days 2-7 $(9,11,18)$.

The sharp decrease in $\mathrm{V}_{\mathrm{d}}$ (Fig. $1 B$ ) with development was expected, given the developmental increase of CBG under these conditions $(1,2,9,19)$. Koch et al. (11) found $\mathrm{V}_{\mathrm{d}}$ to be: 1 ) reduced under conditions of a thyroxine-induced increase in plasma concentration of $\mathrm{CBG}$ at day 6 ; and 2) increased under conditions of a decrease in plasma CBG after birth due to the disappearance of maternally derived CBG (18). In a comparison of 2- and 7-day rats, an approximate 6 -fold increase in $\mathrm{V}_{\mathrm{d}}$ (expressed per $\mathrm{g} \mathrm{BW}$ ) coincided with a similar decrease in concentration of circulating CBG (18). Our data for $V_{d}$ (expressed in $\mathrm{ml}$ only) at day 12 agree reasonably well with published data $(9,18)$, although comparison is difficult because of lack of correspondence in ages and experimental design. Protein binding and tissue sequestration of corticosterone necessarily lead to unusual values for $V_{d}$ which can be greater than total body water $(20,21)$. As such, $V_{d}$ becomes essentially a mathematical concept, but one that can be used to monitor changes occurring with development. Inasmuch as $V_{d}$ is the principal determinant of the decline in the MCR for corticosterone with increasing age, the ultimate determinant of the developmental rise of circulating corticosterone would appear to be the concomitant rise of its plasma binding protein. This suggestion is consistent with the fact that during the developmental period, corticosterone and CBG respond in concert to hyper- and hypothyroidism (22).

The effect of the stress engendered by the experimental method has been largely neglected in the literature. Any process involving anesthesia, intravenous injection, and a subsequent recovery period may perturb basal conditions. It is likely that individual stressors affect the hypothalamic/pituitary/adrenal axis differently and that a generalized statement on the effect of stress as encountered in our system cannot be made. Other investigators have drawn conclusions as to the effect of specific stresses in their situations. Maickel et al. (23) have shown a lack of effect of cold stress on the metabolism and distribution of tracer doses of ${ }^{3} \mathrm{H}$-corticosterone in the adult rat. Manin and DeLost (24) demonstrated that neurotrophic stress increased MCR through increased $V_{d}$ in the conscious guinea pig. Given the developmental increase in the stress response in the rat $(1,25)$, similar effects on MCR and $V_{d}$ would result in a pattern of response opposite to that seen in Figure 1. Finally, Herbst et al. (26) showed that repeated anesthesia in adult rats had no effect on in vitro reduction of ring $\mathrm{A}$ of corticosterone. At best, the effects of the stress engendered by our system on the determination of all kinetic parameters are uncertain, and it remains to be seen if the MCR determined in such a manner is an adequate indicator of hormone clearance under basal conditions.

It is commonly assumed that only free corticosteroid is available for entry into tissue $(10,27,28)$. There is an increasing body of evidence indicating that CBG-bound corticosteroids are available for transport into rat liver (29-32) and peripheral tissues such as rabbit brain (33). Pardridge (34) suggests that in the rat there are microcirculatory mechanisms that catalyze the enhanced dissociation of corticosterone from CBG. Thus, the concentration of exchangeable hormone at the capillary/tissue level may be far greater than the concentration of unbound hormone as measured in plasma from trunk blood. Nevertheless, our data showing that the $t_{1 / 2}$ for the free fraction of corticosterone is always greater than $t_{1 / 2}$ for the bound fraction suggest that bound corticosterone may be preferentially metabolized. Tissue uptake of CBG-bound corticosterone is consistent with the presence of intracellular CBG or CBG-like molecules in various glucocorticoid target organs $(35,36)$. Immunocytochemical localization of intracellular CBG has been shown in rat (37) and guinea pig (38) tissues, but there has been some controversy as to the adequacy of experimental controls. More recently, in well-controlled studies, CBG has been localized immunocytochemically in pituitary cells (28) of the guinea pig and in liver cells, among other organs, in the rat (39). In addition, a CBG-like molecule has been identified on plasma membranes of liver (40) and pituitary (41) in the rat. Hyrb et al. (42) have suggested that the presence of a CBG membrane receptor would simultaneously offer a mechanism for the internalization of $\mathrm{CBG}$ through receptor-mediated endocytosis and a reason for the intracellular localization of CBG. The demonstrations of specific binding of human CBG to cell membranes of the human prostate as well as several monkey tissues suggest that $\mathrm{CBG}$ may be involved in the transport of steroid hormones into target tissues (42). Such a mechanism could contribute to the shorter $t_{1 / 2}$ for total corticosterone in older animals having a greater proportion of bound corticosterone 


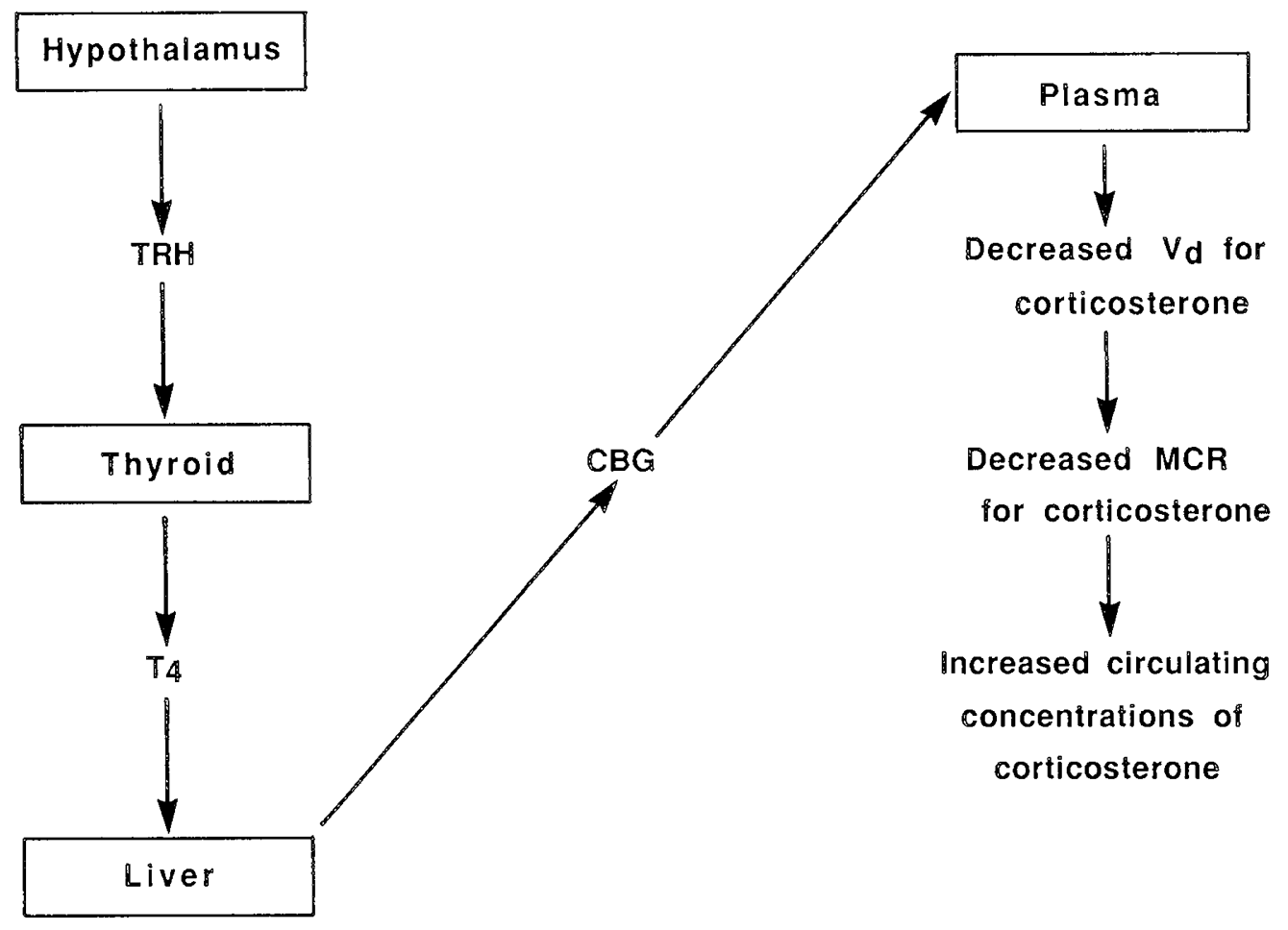

Fig. 4. Proposed scheme for regulation of the developmental increase of circulating corticosterone in the infant rat.

(Fig. 3). Increased CBG binding could serve to specifically deliver corticosterone to target cells with $\mathrm{CBG}$ receptors, such as the liver.

In summary, we have confirmed our previous suggestion that the effect of postnatal age on circulating concentrations of corticosterone in the rat is exerted through a decrease in MCR. The decrease in MCR is due to declining $V_{d}$ which we suggest is effected through the increasing concentration of $\mathrm{CBG}$ with development. Taken together with previous studies which showed that the ontogenic rise of CBG is controlled by the prior surge of thyroxine $(19,22,43)$, these data suggest that the increase of circulating corticosterone that occurs in the rat during the 2 nd and $3 \mathrm{rd}$ postnatal wk is ultimately controlled by the hypothalamus. As shown in Figure 4, the mechanism of this control would be via the pituitary/thyroid/liver axis rather than the pituitary/ adrenal axis.

Acknowledgments. The authors gratefully acknowledge the help of Dr. Stuart Feldman, Department of Pharmaceutics, University of Houston, in the analysis of data for Figure 1. They also thank Marilyn Stevens for her expert assistance in manuscript preparation.

\section{REFERENCES}

1. Henning SJ 1978 Plasma concentrations of total and free corticosterone during development in the rat. Am $\mathrm{J}$ Physiol 235:E451-E456

2. Vallette G, Delorme J, Bernassayag C, Savu L, Nunez EA, Meijs-Roelofs HMA, Kramer P 1982 Developmental patterns of levels of corticosterone and of corticosterone binding in the serum of female rats: effects of ovariectomy and adrenalectomy. Acta Endocrinol 101:442-451

3. Henning SJ, Leeper LL, Dieu DN 1986 Circulating corticosterone in the infant rat: the mechanism of age and thyroxine effects. Pediatr Res 20:87-92

4. Guillet R, Michaelson SM 1978 Corticotropin responsiveness in the neonatal rat. Neuroendocrinology 27:119-125

5. Walker C-D, Perrin M, Vale W, Rivier C 1986 Ontogeny of the stress response in the rat: role of the pituitary and the hypothalamus. Endocrinology 118:1445-1451

6. Henning SJ, Genovese GM 1985 Postnatal development of cholesterol ester hydrolase activity in the rat adrenal. J Steroid Biochem 22:803-808

7. Tait JF, Burstein S 1964 In vivo studies of steroid dynamics in man. In: Pincus G, Thimann KV, Astwood EB (eds) The Hormones. Academic Press, New
York, pp 44l-557

8. Gala RR, Westphal U 1965 Corticosteroid-binding globulin in the rat: studies on the sex difference. Endocrinology 77:841-851

9. Koch B 1969 Fraction libre de la corticosterone plasmatique et reponse hypophysosurrenalienne au stress durant la periode post-natale chez le rat. Horm Metab Res 1:301-308

10. Westphal U 1983 Steroid-protein interaction: from past to present. J Steroid Biochem 19:1-15

11. Koch B, Lutz B, Schmitt G, Mialhe C 1970 Influence of transcortin on degradation and tissue uptake of corticosterone in the infant rat. Horm Metab Res 2:292-297

12. Rocci ML Jr, Jusko WJ 1983 LAGRAN program for area and moments in pharmacokinetic analysis. Comp Prog Biomed 16:203-216

13. Martin CE, Cake MH, Hartmann PE, Cook IF 1977 Relationship between foetal corticosteroids, maternal progesterone and parturition in the rat. Acta Endocrinol 84:167-176

14. Glenister DW, Yates FE 1961 Sex differences in the rate of disappearance of corticosterone-4- $\mathrm{C}^{14}$ from plasma of intact rats: further evidence for the influence of hepatic $\Delta^{4}$-steroid hydrogenase activity on adrenal cortical function. Endocrinology 68:747-758

15. Schapiro S, Percin CJ, Kotichas FJ 1971 Half-life of plasma corticosterone during development. Endocrinology 89:284-286

16. Kitay JI 1961 Sex differences in adrenal cortical secretion in the rat. Endocrinology 68:818-824

17. Labrie F, Pelletier G, Labrie R, Ho-Kim MA, Delgado A, MacIntosh B, Fortier C 1968 Liaison transcortine-corticosterone et controle de l'activite hypophyso-surrenalienne chez le rat. Interactions hypophyse-thyroide-surrenalesgonades. Ann Endocrinol 29:29-43

18. Koch B, Lutz B, Mialhe C 1969 Taux plasmatique et metabolisme de la corticosterone pendant la periode post-natale chez le rat. J Physiol (Paris) $61: 142$

19. D'Agostino JB, Henning SJ 1981 Hormonal control of postnatal development of corticosteroid-binding globulin. Am J Physiol 240:E402-E406

20. Bowman WC, Rand MJ 1980 Absorption, excretion, distribution and metabolism of drugs: biopharmaceutics and pharmacokinetics. In: Textbook of Pharmacology. Blackwell Scientific Publications, London, pp 40.18-40.30

21. Goldstein A, Aronow L, Kalman SM 1974 The absorption, distribution and elimination of drugs. In: Principles of Drug Action: The Basis of Pharmacology. John Wiley and Sons, New York, pp 154-210

22. D'Agostino JB, Henning SJ 1982 Role of thyroxine in coordinate control of corticosterone and CBG in postnatal development. Am J Physiol 242:E33E39

23. Maickel RP, Bush MT, Jondorf WR, Miller FP, Gillette JR 1966 Factors influencing the metabolism and distribution of corticosterone-1,2- ${ }^{3} \mathrm{H}$ in the rat. Mol Pharmacol 2:491-498

24. Manin M, DeLost P 1981 Effects of acute neurotrophic stress on peripheral metabolism of cortisol in conscious male guinea-pigs. J Endocrinol 89:443449 
25. Schoenfeld NM, Leathem JH, Rabii J 1980 Maturation of adrenal stress responsiveness in the rat. Neuroendocrinology 3l:10 $1-105$

26. Herbst AL, Yates FE, Glenister DW, Urquhart J 1960 Variations in hepatic inactivation of corticosterone with changes in food intake: An explanation of impaired corticosteroid metabolism following noxious stimuli. Endocrinology 67:222-238

27. Lan NC, Karin M, Nguyen T, Weisz A, Birnbaum MJ, Eberhardt NL, Baxter JD 1984 Mechanisms of glucocorticoid hormone action. J Steroid Biochem 20:77-88

28. Perrot-Applanat M, Racadot O, Milgrom E 1984 Specific localization of plasma corticosteroid-binding globulin immunoreactivity in pituitary corticotrophs. Endocrinology 115:559-569

29. Keller N, Richardson UI, Yates FE 1969 Protein binding and the biological activity of corticosteroids: In vivo induction of hepatic and pancreatic alanine aminotransferases by corticosteroids in normal and estrogen-treated rats. Endocrinology 84:49-62

30. Pardridge WM, Mietus LJ 1979 Transport of protein-bound steroid hormones into liver in vivo. Am $\mathrm{J}$ Physiol 237:E367-E372

31. Pardridge WM, Sakiyama R, Judd HL 1983 Protein-bound corticosteroid in human serum is selectively transported into rat brain and liver in vivo. $\mathbf{J}$ Clin Endocrinol Metab 57:160-165

32. Rosner W, Hochberg R 1972 Corticosteroid-binding globulin in the rat: isolation and studies of its influence on cortisol action in vivo. Endocrinology 91:626-632

33. Pardridge WM, Eisenberg J, Fierer G, Kuhn RW 1986 CBG does not restrict blood-brain barrier corticosterone transport in rabbits. Am $\mathbf{J}$ Physiol 251:E204-E208
34. Pardridge WM 1987 Plasma protein-mediated transport of steroid and thyroid hormones. Am J Physiol 252:E157-E164

35. De Kloet ER, McEwen BS 1976 A putative glucocorticoid receptor and transcortin-like macromolecule in pituitary cytosol. Biochim Biophys Acta 421:115-123

36. Koch B, Lutz B, Briaud B, Mialhe C 1976 Heterogeneity of pituitary glucocorticoid binding. Evidence for a transcortin-like compound. Biochim Biophys Acta 444:497-507

37. Siiteri PK, Murai JT, Hammond GL, Nisker JA, Raymoure WJ, Kuhn RW 1982 The serum transport of steroid hormones. Rec Prog Horm Res 38:457510

38. Perrot-Applanat M, David-Ferreira JF, David-Ferreira KL 1981 Immunocytochemical localization of corticosteroid-binding globulin (CBG) in guinea pig hepatocytes. Endocrinology 109:1625-1633

39. Kuhn RW, Green AL, Raymoure WJ, Siiteri PK 1986 Immunocytochemical localization of corticosteroid-binding globulin in rat tissues. $\mathrm{J}$ Endocrinol 108:31-36

40. Suyemitsu T, Terayama H 1975 Specific binding sites for natural glucocorticoids in plasma membranes of rat liver. Endocrinology 96:1499-1508

41. Koch B, Lutz-Bucher B, Briaud B, Mialhe C 1978 Specific interaction of corticosteroids with binding sites in the plasma membranes of the rat anterior pituitary gland. J Endocrinol 79:215-222

42. Hryb DJ, Khan MS, Romas NA, Rosner W 1986 Specific binding of human corticosteroid-binding globulin to cell membranes. Proc Natl Acad Sci USA 83:3253-3256

43. D'Agostino JB, Henning SJ 1982 Postnatal development of corticosteroidbinding globulin: effects of thyroxine. Endocrinology 111:1476-1148 